\title{
Antimicrobial nanocapsules: from new solvent-free process to in vitro efficiency
}

This article was published in the following Dove Press journal:

International Journal of Nanomedicine

19 September 2014

Number of times this article has been viewed

\author{
Julie Steelandt ${ }^{1}$ \\ Damien Salmon ${ }^{1,2}$ \\ Elodie Gilbert' \\ Eyad Almouazen ${ }^{3}$ \\ François NR Renaud ${ }^{4}$ \\ Laurène Roussel' \\ Marek Haftek ${ }^{5}$ \\ Fabrice Pirot ${ }^{1,2}$ \\ 'University Claude Bernard Lyon I, \\ Faculty of Pharmacy, Fundamental, \\ Clinical and Therapeutic Aspects \\ of Skin Barrier Function, FRIPharm, \\ Laboratoire de Pharmacie Galénique \\ Industrielle, ${ }^{2}$ Hospital Pharmacy, \\ FRIPharm, Hospital Edouard Herriot, \\ Hospices Civils de Lyon, ${ }^{3}$ Laboratoire \\ d'Automatique et de Génie des \\ Procédés, University Claude Bernard \\ Lyon I, ${ }^{4}$ University Claude Bernard \\ Lyon I, UMR CNRS 55IO/MATEIS, \\ ${ }^{5}$ University Claude Bernard Lyon I, \\ Faculty of Pharmacy, Fundamental, \\ Clinical and Therapeutic Aspects \\ of Skin Barrier Function, FRIPharm, \\ Laboratoire de Dermatologie, Lyon, \\ France
}

Correspondence: Fabrice Pirot Laboratoire de Pharmacie Galénique Industrielle, EA 4169: Fundamental, Clinical and Therapeutic Aspects of Skin Barrier Function, Faculty of Pharmacy, University Claude Bernard Lyon I, 8 Avenue Rockefeller, Lyon 69373, France Tel +33478777 I67

Fax +33478777 247

Email fabrice.pirot@univ-lyon I.fr

\begin{abstract}
Skin and mucosal infections constitute recurrent pathologies resulting from either inappropriate antiseptic procedures or a lack of efficacy of antimicrobial products. In this field, nanomaterials offer interesting antimicrobial properties (eg, long-lasting activity; intracellular and tissular penetration) as compared to conventional products. The aim of this work was to produce, by a new solvent-free process, a stable and easily freeze-dryable chlorhexidine-loaded polymeric nanocapsule (CHX-NC) suspension, and then to assess the antimicrobial properties of nanomaterials. The relevance of the process and the physicochemical properties of the CHXNCs were examined by the assessment of encapsulation efficiency, stability of the nanomaterial suspension after 1 month of storage, and by analysis of granulometry and surface electric charge of nanocapsules. In vitro antimicrobial activities of the CHX-NCs and chlorhexidine digluconate solution were compared by measuring the inhibition diameters of two bacterial strains (Escherichia coli and Staphylococcus aureus) and one fungal strain (Candida albicans) cultured onto appropriate media. Based on the findings of this study, we report a new solvent-free process for the production of nanomaterials exhibiting antimicrobial activity, suitable stability, and easily incorporable as a new ingredient in various pharmaceutical products.
\end{abstract}

Keywords: nanomaterial, nanocapsules, antiseptic, chlorhexidine, solvent-free process

\section{Introduction}

Chlorhexidine (CHX) is a bis-biguanide showing broad-spectrum antiseptic activity against Gram-positive and Gram-negative bacteria, and fungi. Its efficient antimicrobial activity finds numerous pharmaceutical applications, notably in mucosal and cutaneous antisepsis. ${ }^{1}$ Oral mucosa antisepsis is challenging, since saliva bathing and enzymes are responsible for the clearance and degradation of drugs. ${ }^{2}$ In this field, CHX is widely used, and its efficacy has been fully described. ${ }^{3,4}$ However, oral mucosa administration of CHX exhibits potential side effects (eg, tooth staining, taste alteration, burning sensation, low bioavailability ${ }^{5}$ ), so original formulations were developed (eg, gels, varnishes, mucoadhesive tablets, and orthodontic materials), allowing controlled drug release. ${ }^{3,6,7}$ Furthermore, the use of antiseptic agents is mandatory to prevent surgical site infection and to reduce nosocomial infections responsible for morbidity and mortality incidence and growing economic pharmaceutical care. ${ }^{8,9}$ In this context, CHX was proven efficient in reducing the occurrence of resistant bacterial strains, especially methicillin-resistant Staphylococcus aureus and extended-spectrum $\beta$-lactamase, ${ }^{10}$ and is recognized to produce an efficient, immediate, and sustained antiseptic effect maintained beneath surgical gloves. ${ }^{11}$ However, compliance with antiseptic use is followed by only $50 \%$ of medical and nursing staff in care units. ${ }^{12}$ Reiterated and time-consuming applications, as well as the misuse of antiseptics, reveal the necessity of a new strategy for a rapid and sustained antiseptic activity. ${ }^{13-15}$ 
An alternative to conventional formulations is found in nanomedicine supporting drug targeting and sustained pharmacological activity. ${ }^{16}$ In this field, polymeric nanocapsules (NCs) present many advantages, such as their ability to display immediate and sustained drug release while preventing chemical degradation. ${ }^{17}$ In previous publications, we have provided an in vitro release study, an ex vivo cutaneous permeability study, an in vivo human sustained antibacterial efficiency study, and a minimum inhibitory concentration determination for $\mathrm{CHX}$-loaded poly- $\varepsilon$-caprolactone (PCL) NCs. ${ }^{18-20}$ However, CHX-NCs were prepared by conventional interfacial deposition, where PCL was dissolved in organic solvent, the latter being therefore eliminated from the aqueous phase by evaporation and multiple purification steps questioning the presence of solvent residue and the feasibility of industrial scale-up. ${ }^{21}$ The main objective of this study was to prepare by an original solvent-free process a stable and easily freeze-dryable CHX-NC suspension as a new antimicrobial nanomaterial. Physicochemical and granulometric characterization of $\mathrm{CHX}-\mathrm{NCs}$ is provided that correlates with previous findings. Furthermore, the in vitro antimicrobial efficiency of CHX-NCs was verified using an agar-diffusion method m $^{22,23}$ and compared to $1 \% \mathrm{CHX}$ digluconate aqueous solution.

\section{Materials and methods Materials}

CHX base was purchased from Inresa (Bartenheim, France), Montanox 80 (polysorbate 80, hydrophilic surfactant) was given by Seppic (Castres, France), and Lutrol ${ }^{\circledR}$ F68 (poloxamer 188, molecular mass 7,680-9,510 g/mol, 81\% polyoxyethylene units) was provided by BASF (Ludwigshafen, Germany). Labrafil ${ }^{\circledR}$ M1944CS (mixture of mono-, di-, and triglycerides and mono- and difatty esters of polyethylene glycol 300) and Plurol ${ }^{\circledR}$ Oléique CC 497 (polyglyceryl-6 dioleate) were provided by Gattefossé (St Priest, France). PCL (molecular mass $\sim 80,000 \mathrm{Da}$ ) was purchased from Sigma-Aldrich (St Louis, MO, USA). Müller-Hinton agar plates and bacterial and fungal strains were provided by Nosoco Tech (Lyon, France).

\section{Nanocapsule production}

In a recent patent, we reported a new solvent-free process for the production of polymeric NCs. ${ }^{24}$ Briefly, a hydrophobic crystalline or amorphous polymer (ie, PCL) was melted or dispersed above the glass-transition temperature in an oily mixture containing triglycerides and a lipophilic surfactant. Then, the oily phase was mixed in an aqueous gel containing hydrophilic surfactant, enabling the formation of polymeric NCs suspended in gelified suspension. In the present study, the oily phase was a mixture of Plurol Oléique CC 497 (HLB =6; 4 g), and Labrafil M1944CS (HLB =4; $0.36 \mathrm{~g})$ heated at $60^{\circ} \mathrm{C}-70^{\circ} \mathrm{C}$. Afterward, PCL $(0.37 \mathrm{~g})$ and CHX base ( $1 \mathrm{~g})$ were introduced into the oily mixture and mechanically stirred (600 rpm) until a homogeneous and clear dispersion was obtained. Also, poloxamer 188 (34 g) hydrogel was prepared in a $0.15 \%$ Montanox $80(\mathrm{HLB}=15)$ aqueous solution $(60.27 \mathrm{~g})$ and heated at $60^{\circ} \mathrm{C}-70^{\circ} \mathrm{C}$. Finally, the oily mixture and hydrogel were mixed under mechanical stirring (600 rpm), allowing the spontaneous formation of polymeric NCs. The theoretical CHX concentration in $\mathrm{NC}$ suspension was $1 \%$ (weight/weight [w/w]). CHX-NCs in suspension represented $5.73 \%(\mathrm{w} / \mathrm{w})$.

\section{Freeze-drying of nanocapsule suspension}

$\mathrm{CHX}-\mathrm{NC}$ suspensions was frozen for 48 hours at $-80^{\circ} \mathrm{C}$, then freeze-dried for 24 hours (Heto Power Dry LL3000 freezedryer; Thermo Fisher Scientific, Waltham, MA, USA). Additionally, freeze-dried powder was passed through a $2 \mathrm{~mm}$ sieve. Rehydration of $0.5 \mathrm{~g}$ freeze-dried CHX-NC powder in $10 \mathrm{~mL}$ of purified water enabled the restitution of the initial CHX-NC suspension.

\section{Granulometric analysis}

Particle size, polydispersity index, and zeta potential were determined using a coupled granulometer and zeta-potential analyzer (Zetasizer Nano ZS, Malvern Instruments, Malvern, UK). This instrument enables the measurement by dynamic light scattering of particle sizes between $0.6 \mathrm{~nm}$ to $8.9 \mu \mathrm{m}$ (detector angle $173^{\circ}$, wavelength $633 \mathrm{~nm}$ ). Zeta potential is achieved by laser Doppler electrophoresis (maximum conductivity $200 \mathrm{mS} / \mathrm{cm}$ ). Adequate dilutions of each formulation in demineralized water were analyzed at $25^{\circ} \mathrm{C} \pm 2{ }^{\circ} \mathrm{C}$ in a dedicated vial (Plastibrand ${ }^{\mathrm{TM}} 70 \mu \mathrm{L}$ micro; Sigma-Aldrich). Measurements were performed on three different batches of CHX-NC suspensions. Each measurement was repeated ten times, and results are expressed as means of ten measurements \pm standard deviation. ${ }^{25}$

\section{High-performance liquid-chromatography analysis}

CHX was analyzed by reverse-phase chromatography using high-performance liquid chromatography (HPLC; 1200 series; Agilent Technologies, Santa Clara, CA, USA) according to a method described previously. ${ }^{19}$ A C18 column was used (Zorbax, $150 \times 3 \mathrm{~mm}, 3.5 \mu \mathrm{m}$ particle size; Agilent 
Technologies). The mobile phase was composed of acetonitrile and $30 \mathrm{mM}$ sodium acetate buffer (1:1, volume/ volume $[\mathrm{v} / \mathrm{v}])$ adjusted to $\mathrm{pH} 3.3$ with acetic acid (96\%). Samples were filtered through $0.45 \mu \mathrm{m}$ polyvinylidene difluoride membranes (Millex ${ }^{\circledR}$ filter; EMD Millipore, Billerica, MA, USA) and degassed by ultrasonication. The injected sample volume was $40 \mu \mathrm{L}$, and the flow rate of the mobile phase was $0.8 \mathrm{~mL} /$ minute. The retention time of $\mathrm{CHX}$ detected at $260 \mathrm{~nm}$ was 1.3 minutes. For concentrations between 6.25 and $300 \mu \mathrm{g} / \mathrm{mL}$, chromatograms were linear with a correlation factor of 0.999 . The limit of quantification of CHX was $\sim 20 \mathrm{ng} / \mathrm{mL}$.

\section{Determination of encapsulation efficiency} Total CHX in suspension and freeze-dried powder

The total amount of CHX in suspension and freeze-dried powder was determined by HPLC analysis. CHX-NC suspension $(1 \mathrm{~mL})$ was diluted in the mobile phase (1:100), and freeze-dried CHX-NC powder ( $0.5 \mathrm{~g})$ was firstly dispersed in $10 \mathrm{~mL}$ mobile phase and then diluted in the mobile phase (1:100). Complete dissolution of NCs and subsequent CHX release were ensured by dilution in the mobile phase. Samples were filtered before analysis, as described in the "Highperformance liquid-chromatography analysis" section.

\section{Unencapsulated $\mathrm{CHX}$ in suspension and freeze-dried powder}

The unencapsulated CHX amount in the CHX-NC suspension was determined by dilution of the CHX-NC suspension in purified water $(1: 100)$, then filtration through an Ultrafree $^{\circledR}$-CL filter $(0.1 \mu \mathrm{m}$, polyvinylidene difluoride membrane; EMD Millipore), which was centrifuged (4 minutes, $6000 \mathrm{~g})$. Thereafter, the collected unencapsulated CHX in ultrafiltrate was assayed by HPLC, as described in the "High-performance liquid-chromatography analysis" section. ${ }^{19}$ Similarly, freeze-dried CHX-NC powder $(0.5 \mathrm{~g})$ dispersed in $10 \mathrm{~mL}$ of purified water and then diluted in purified water $(1: 10)$ was ultrafiltrated, as described previously.

\section{Encapsulation efficiency}

The encapsulation efficiency (EE) of the $\mathrm{CHX}$ input $\left(\mathrm{Q}_{\mathrm{CHX} \text { input }}\right)$ was calculated from the total CHX amount in the CHX-NC suspension $\left(\mathrm{Q}_{\mathrm{CHX}-\mathrm{NC} \text { suspension }}\right)$, and the $\mathrm{CHX}$ amount recovered in ultrafiltrate $\left(\mathrm{Q}_{\mathrm{CHX} \text { ultrafiltrated }}\right)$ calculated as follows:

$$
\mathrm{EE}(\%)=\frac{\mathrm{Q}_{\mathrm{CHX}-\mathrm{NC} \text { suspension }}-\mathrm{Q}_{\mathrm{CHX} \text { ultrafiltrated }}}{\mathrm{Q}_{\mathrm{CHX} \text { input }}} \times 100 .
$$

\section{Morphology of nanocapsule suspensions and freeze-dried powder}

CHX-NC and freeze-dried CHX-NC morphology was studied by using an S800 scanning electron microscope (Hitachi, Tokyo, Japan) after gold-palladium coating.

\section{Study of $\mathrm{CHX}-\mathrm{NC}$ suspension stability}

CHX-NC suspension stability was assessed using a Turbiscan ${ }^{\mathrm{TM}}$ Classic MA 2000 (Formulaction, L'Union, France), in which the CHX-NC suspension filled aseptically in a sterile glass tube (filling height $50 \mathrm{~mm}$ ) was scanned vertically by an $850 \mathrm{~nm}$ incident beam (ie, analysis of backscattering detection at a $180^{\circ}$ angle). Turbiscan measurements were performed each day during the first week and every 3 days thereafter for 1 month while in storage at an ambient temperature $\left(20^{\circ} \mathrm{C} \pm 5^{\circ} \mathrm{C}\right) .{ }^{25,26}$ Additionally, granulometric analysis was performed as described in the "Granulometric analysis" section after 1 month's storage at an ambient temperature.

\section{In vitro antimicrobial efficiency}

The antimicrobial efficiency of the CHX-NC suspension and $\mathrm{CHX}-\mathrm{NC}$ freeze-dried powder was compared to $\mathrm{CHX}$ digluconate solution (1\%) by using an adapted antibiogram test. ${ }^{27,28}$ The choice of bacterial strains was driven by European Pharmacopoeia recommendations. ${ }^{29}$ In vitro antimicrobial activity of CHX nanomaterials and CHX digluconate solution was determined against clinically isolated bacterial (Escherichia coli, Staphylococcus aureus) and fungal (Candida albicans) strains on Müller-Hinton and Sabouraud media, respectively. Impregnated disks of tested formulations $(2 \mu \mathrm{L})$ were deposited onto the surface of the culture media, and inhibition diameters of strains exposed to the CHX-NC suspension, freeze-dried CHX-NC powder dispersed in purified water, the CHX digluconate solution, and an unloaded PCL NC suspension (ie, NCs produced as detailed in the "Nanocapsule production" section without $\mathrm{CHX}$ load), which were measured after 24 hours at $37^{\circ} \mathrm{C}$.

\section{Statistical analysis}

The granulometry and surface electric charge of the CHX-NC suspension were compared before and after 1) an immediate freeze-drying process by using the nonparametric MannWhitney-Wilcoxon test for unpaired data and 2) 1 month of storage by using the nonparametric Mann-WhitneyWilcoxon test for paired data. The Kruskal-Wallis rank-sum test was performed for multiple comparisons between the antibacterial/antifungal activity of formulations. The level of statistical significance was chosen as $P<0.05$. 


\section{Results}

\section{Formulation and characterization} of $\mathrm{CHX}-\mathrm{NC}$ suspension

\section{and freeze-dried powder}

The CHX-NC suspension was characterized macroscopically as a homogeneous milky dispersion easily freeze-dried and sieved as a white powder (Figure 1D). Granulometry and surface properties of CHX-NC suspensions and freeze-dried CHX-NC powder are reported in Table 1. Submicronic size and mid-range polydispersity of the CHX-NC suspension were confirmed before and after 1 month of storage at an ambient temperature. As reported in our previous study, CHX-NCs exhibited a permanent positive surface electric charge throughout storage, due to $\mathrm{CHX}$ dissociation at the water-polymeric wall interface compared to negatively charged unloaded NCs. ${ }^{19}$ No significant differences in granulometry and surface properties were observed between batches $(n=3)$ of CHX-NC suspensions. Furthermore, immediate freeze-drying of CHX-NC suspensions did not significantly affect either granulometric or surface electric charge parameters. Electron microscopy observation of CHX-NC suspensions confirmed the nanometric spherical shape of CHX-NCs (Figure 1, A and B). The aggregated structure of freeze-dried $\mathrm{CHX}-\mathrm{NC}$ powder was evident from scanning electron microscopy (Figure 1C).

Recovery of the initial CHX input was found between $85 \%$ and $89 \%$, respectively, in suspension and after freezedrying process. Total recovery was assumed as CHX loss

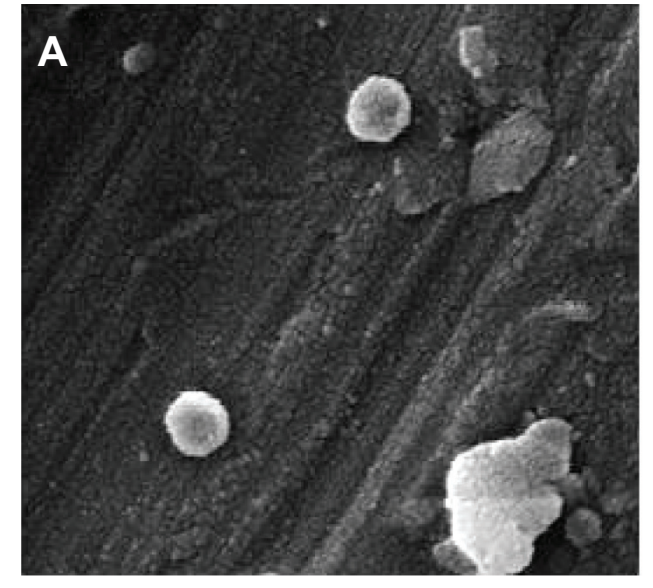

$500 \mathrm{~nm}$

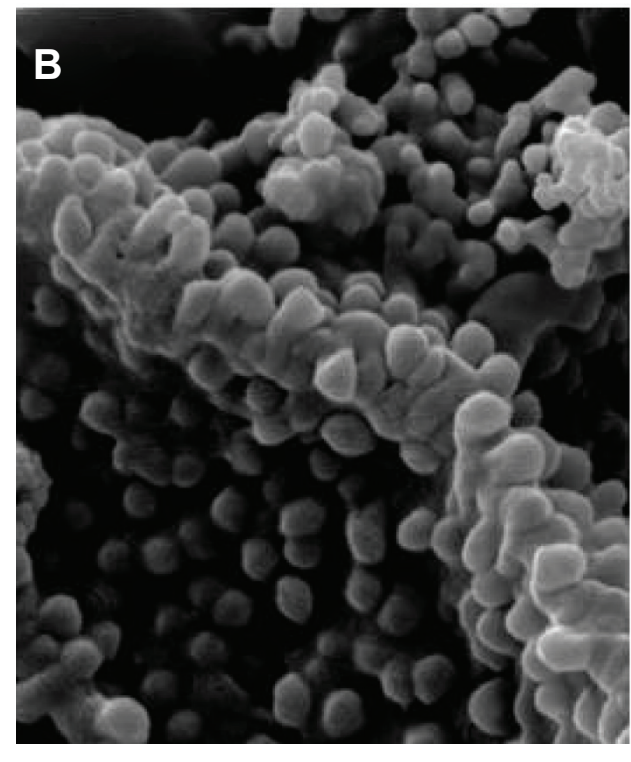

$\overline{1 \mu \mathrm{m}}$
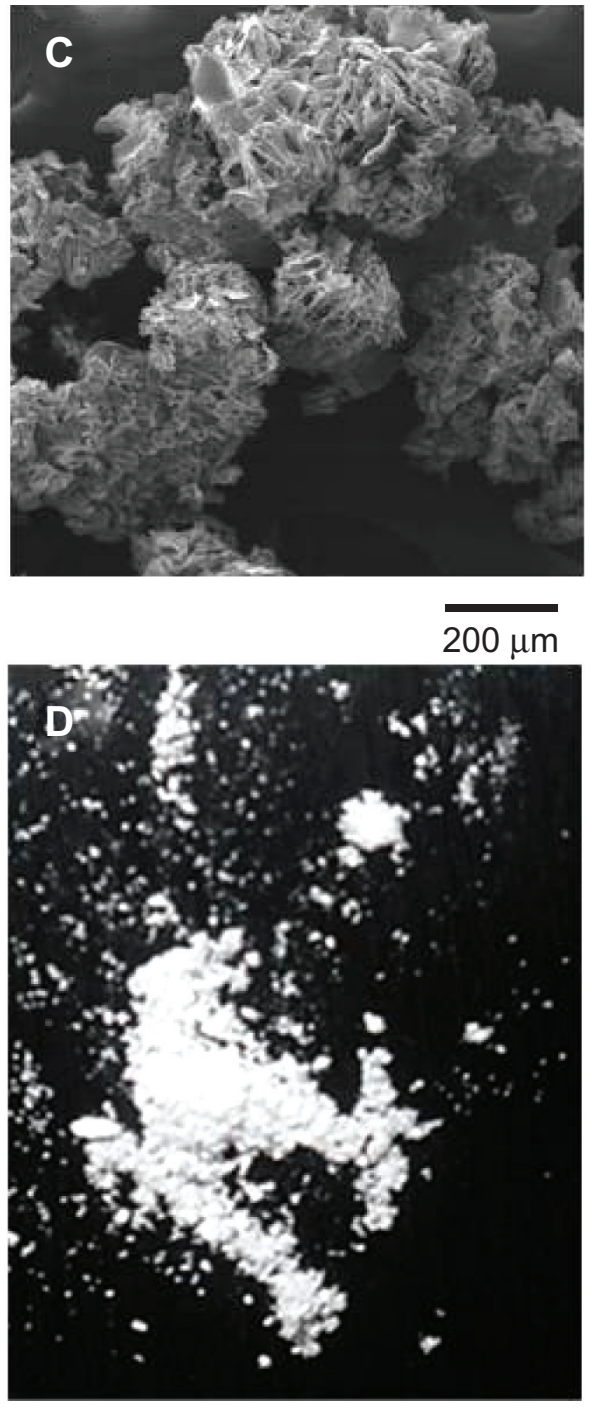

$1 \mathrm{~cm}$

Figure I Scanning electron microscopy images of (A) chlorhexidine-loaded nanocapsules (CHX-NCs), (B) CHX-NC suspension, (C) freeze-dried CHX-NC powder, and (D) photograph of freeze-dried CHX-NC powder. 
Table I Loading, granulometric, and surface electric properties of chlorhexidine nanocapsule (CHX-NC) suspensions (CHX I\%, I mL) and freeze-dried $\mathrm{CHX}-\mathrm{NC}$ powder ( $\mathrm{CHX} 2.5 \%, 0.5 \mathrm{~g})$

\begin{tabular}{|c|c|c|c|c|c|c|c|c|c|c|c|}
\hline \multirow[t]{2}{*}{ Formulation } & \multicolumn{4}{|c|}{$\mathrm{CHX}$ amount (mg) } & \multirow[t]{2}{*}{ EE (\%) } & \multicolumn{2}{|c|}{$\begin{array}{l}\text { Average size } \\
(\mathrm{nm})\end{array}$} & \multicolumn{2}{|l|}{$10^{2} \mathrm{PI}$} & \multicolumn{2}{|l|}{$\zeta(\mathrm{mV})$} \\
\hline & Input & Recovered & Encapsulated & Ultrafiltrated & & Day 0 & Day 30 & Day 0 & Day 30 & Day 0 & Day 30 \\
\hline $\begin{array}{l}\text { CHX-NC } \\
\text { suspension }\end{array}$ & 10.0 & $8.5 \pm 0.1$ & $6.9 \pm 0.3$ & $1.6 \pm 0.3$ & $69 \pm 3$ & $225 \pm 2$ & $\begin{array}{l}247 \pm 3 \\
\text { (NS) }\end{array}$ & $16 \pm 0.7$ & $\begin{array}{l}19 \pm 0.2 \\
\text { (NS) }\end{array}$ & $18 \pm 5$ & $\begin{array}{l}13 \pm 4 \\
\text { (NS) }\end{array}$ \\
\hline $\begin{array}{l}\text { Freeze-dried } \\
\mathrm{CHX-NC}\end{array}$ & 12.5 & $\mid I . I \pm 0.1$ & $6.2 \pm 1.6$ & $4.9 \pm 1.6$ & $50 \pm 13$ & $\begin{array}{l}224 \pm I \\
\text { (NS) }\end{array}$ & ND & $42 \pm 0.9 *$ & ND & $10 \pm 4 *$ & ND \\
\hline
\end{tabular}

Notes: *Significantly different from $\mathrm{CHX}-\mathrm{NC}$ suspension day 0 group (Wilcoxon test for unpaired data test, $P<0.05$ ). Chlorhexidine amounts are expressed as means \pm standard deviation of at least three experimental determinations. Granulometric data (average size, polydispersity index [PI], and zeta potential [ $\zeta]$ ) are expressed as means \pm standard deviation of at least ten experimental determinations on each batch $(n=3)$. Storage of suspensions was performed at room temperature $\left(20^{\circ} \mathrm{C} \pm 5^{\circ} \mathrm{C}\right)$ and protected from light.

Abbreviations: EE, encapsulation efficiency; NS, not significant; ND, not determined.

inferior or equal to $15 \%$. In order to confirm the relevance of the new solvent-free process, the EE of CHX into polymeric NCs was evaluated from the ratio of unencapsulated CHX to initial input. At the outset, encapsulation of CHX was close to $70 \%$, which was consistent with that determined in previous studies ${ }^{19,21}$ reporting CHX encapsulation in PCL NCs obtained by a conventional interfacial deposition technique involving predissolution of polyester in acetone and a subsequent solvent-evaporation step. Nevertheless, the EE of CHX assessed in freeze-dried CHX-NC powder was found to be lower than that of the CHX-NC suspension. Accordingly, the ultrafiltrated $\mathrm{CHX}$ rate was 2.5 times higher after freeze-drying ( $44 \%)$ than that of the initial CHX-NC suspension ( 18\%). Different assumptions might be advanced to explain these discrepancies, such as a shrinking of nanocapsules during the freezing phase favoring oily mixture diffusion through the NC wall, or a breakage of NCs during freeze-drying releasing oily content into the suspending solution. However, no variation in CHX-NC size was evident, suggesting no dramatic breakage of nanomaterial, but higher polydispersity and lower surface electric charge tended to confirm a reversible and nondestructive shrinking of CHX-NCs following freeze-drying. Turbiscan analysis did not show any sedimentation or creaming in CHX-NC suspensions stored for 1 month, but negligible flocculation was assumed, as a minor variation $(<10 \%)$ of suspension backscattering was observed over 1 month (Figure 2). These results were consistent with granulometry and surface electric charge findings determined after 1 month's storage at an ambient temperature (Table 1).

\section{Antimicrobial activity}

In vitro antimicrobial activity of encapsulated $\mathrm{CHX}$ was compared to CHX digluconate solution against common clinically isolated pathogenic bacterial and fungal strains (Figure 3).
Inhibition diameters of strains exposed to antimicrobial formulations are reported in Table 2, showing no significant difference of antimicrobial activity. However, antibacterial activities of CHX-NC suspensions and freeze-dried CHX-NC powder were slightly more important against S. aureus (5.3 $\pm 0.1 \mathrm{~cm}$ and $5.1 \pm 0.3 \mathrm{~cm}$, respectively) and $E$. coli (6.4 $\pm 2.3 \mathrm{~cm}$ and $5.0 \pm 0 \mathrm{~cm}$, respectively) than CHX digluconate $(3.6 \pm 1.1 \mathrm{~cm}$ and $4.0 \pm 0.9 \mathrm{~cm}$, respectively). As expected, no antimicrobial activity was evident with unloaded NCs.

The minimum inhibitory concentration for CHX-NCs had already been determined in a previous publication. ${ }^{19}$ Only the preparation method was changed: from interfacial polymer deposition following solvent displacement to a solvent-free method. Since NC-characterization results were consistent in both publications, minimum inhibitory concentration was

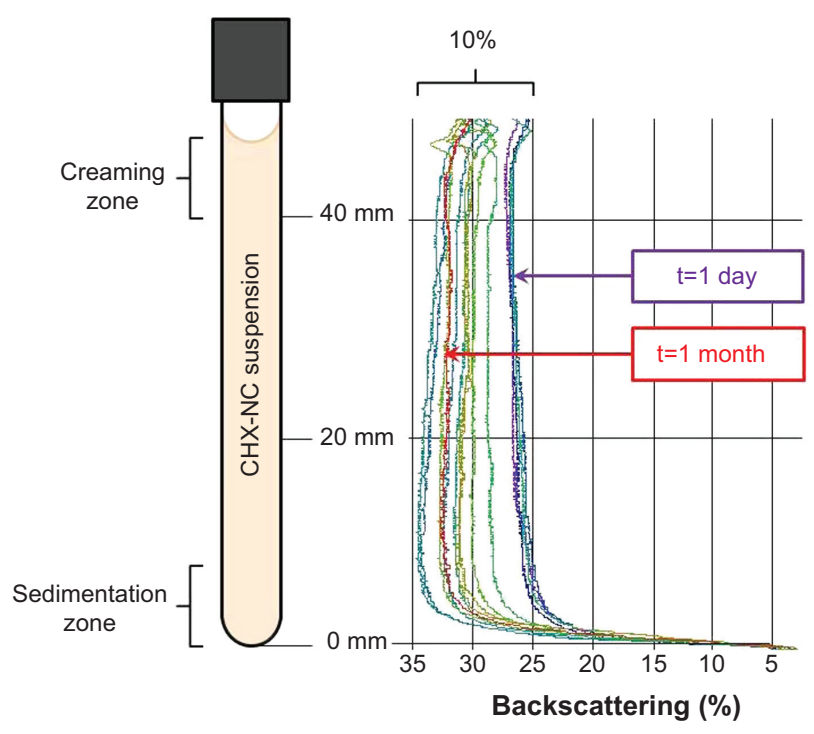

Figure 2 Turbiscan analysis of chlorhexidine-loaded nanocapsule (CHX-NC) suspension backscattering profile evolution over I month of storage at $20^{\circ} \mathrm{C} \pm 5^{\circ} \mathrm{C}$. Notes: There was no evidence of sedimentation or creaming, while flocculation was observed. The extent of flocculation estimated from the variation of backscattering did not exceed $10 \%$. 

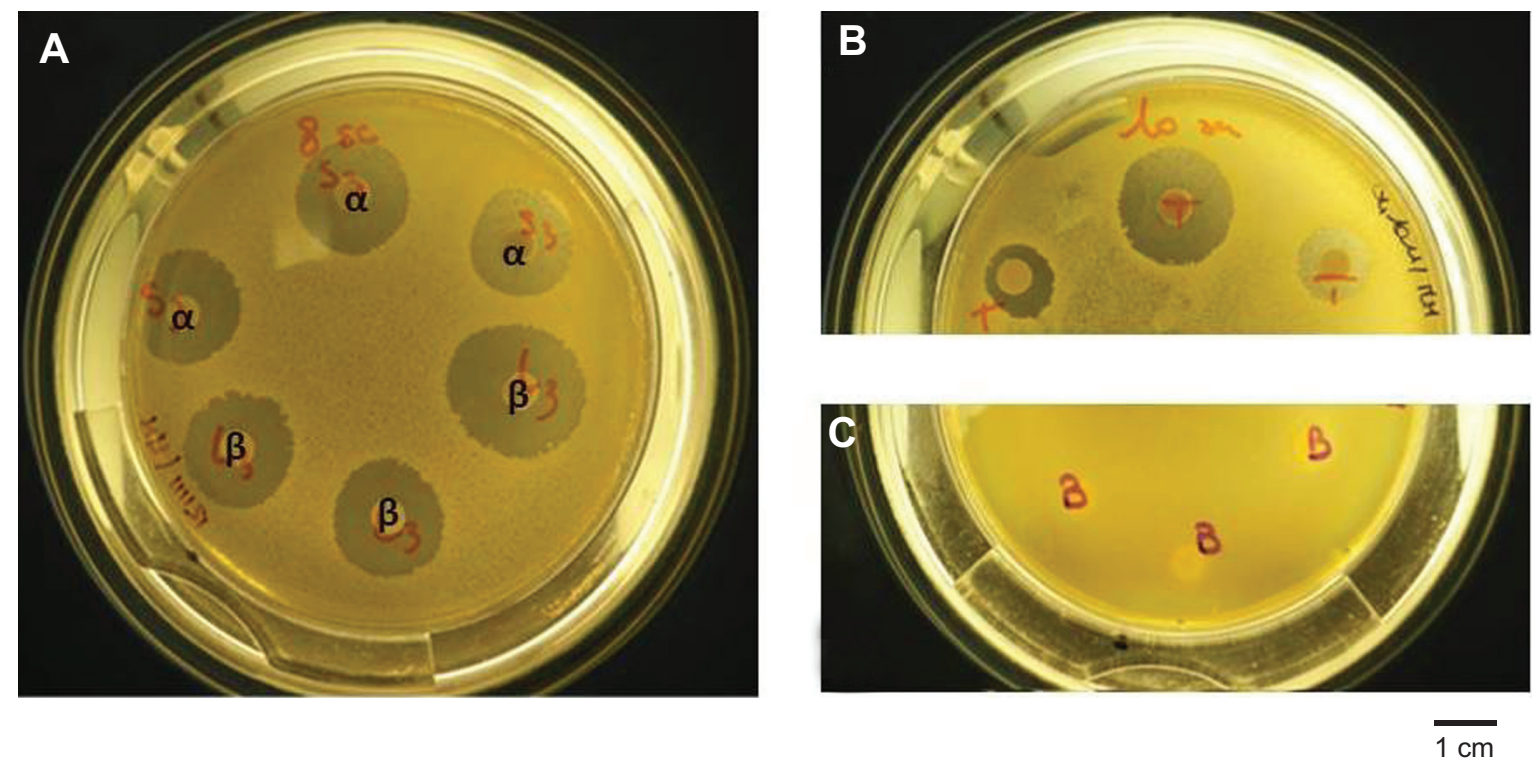

Figure 3A-C Photographs of inhibition diameters of Staphylococcus aureus stain exposed to chlorhexidine (CHX) formulations (2 $\mu \mathrm{L}$ impregnation on paper disks). Notes: (A) $\mathrm{CHX}$ nanocapsule (CHX-NC) formulations (ie, $\mathrm{CHX}-\mathrm{NC}$ suspension $[\alpha]$ and freeze-dried $\mathrm{CHX}-\mathrm{NC}$ powder resuspended in purified water $[\beta]$ ), (B) I\% CHX digluconate solution (positive control), and (C) unloaded NC suspension (negative control).

assumed to be comparable with the new process using the same polymer. Therefore, inhibition diameters obtained by disk diffusion were considered sufficient to verify antiseptic activity, since a complete antiseptic-activity profile had already been determined in a previous publication. ${ }^{18}$

\section{Discussion}

The use of conventional CHX solutions is frequently the subject of controversy (eg, taste masking, low bioavailability), ${ }^{7}$ suggesting the need for new formulation strategies. Polymeric NCs have been extensively studied in the development of drug carriers. However, most NC-preparation methods, such as nanoprecipitation ${ }^{30}$ and emulsification diffusion, ${ }^{31}$ use organic solvents (eg, alcohol, acetone, chloroform, dichloromethane), which must be eliminated at the final step of preparation to obtain a therapeutically usable form. ${ }^{21}$
The use of organic solvents presents an important drawback, due to their toxicity and the need for multiple purification steps, including long-lasting or complex processes, such as evaporation or solvent-diffusion steps. Moreover, solid lipid nanoparticles have been proposed as an alternative to polymeric NCs, with the major advantage of avoiding organic solvents. Solid lipid nanoparticle solvent-free preparation techniques like high-shear or high-pressure homogenization present some limitations, such as energy consumption, drug degradation, and lipid crystallization and modifications. ${ }^{32}$ These considerations are important to take into account in the perspective of industrial scale-up of polymeric and lipid nanoparticles. The method described in this study is solvent-free and consists of a two-step process (ie, separate oily and aqueous phase preparation and mixing) resulting in a stable and freeze-dryable NC suspension

Table 2 Comparison of inhibition diameters of Staphylococcus aureus, Escherichia coli (Müller-Hinton medium), and Candida albicans (Sabouraud medium) strains exposed to chlorhexidine nanocapsule (CHX-NC) suspensions (CHX I\%), freeze-dried CHX-NC powder ( $\mathrm{CHX} 2.5 \%)$ dispersed in purified water ( $\mathrm{CHX} 0.6 \%), 1 \% \mathrm{CHX}$ digluconate solution (positive control), and unloaded nanocapsule suspension (negative control)

\begin{tabular}{|c|c|c|c|}
\hline \multirow[t]{2}{*}{ Formulation } & \multicolumn{3}{|c|}{ Inhibition diameter $(\mathbf{c m})$} \\
\hline & $\begin{array}{l}\text { Staphylococcus } \\
\text { aureus (NS) }\end{array}$ & $\begin{array}{l}\text { Escherichia } \\
\text { coli (NS) }\end{array}$ & $\begin{array}{l}\text { Candida } \\
\text { albicans (NS) }\end{array}$ \\
\hline $\mathrm{CHX}-\mathrm{NC}$ suspension & $5.3 \pm 0.1$ & $6.4 \pm 2.3$ & $3.8 \pm 1.2$ \\
\hline Freeze-dried CHX-NC & $5.1 \pm 0.3$ & $5.0 \pm 0.1$ & $3.2 \pm 0.2$ \\
\hline $\mathrm{CHX}$ digluconate solution & $3.6 \pm 1.1$ & $4.0 \pm 0.9$ & $5.4 \pm 0.8$ \\
\hline Unloaded NC suspension & 0 & 0 & 0 \\
\hline
\end{tabular}

Notes: Data are expressed as means \pm standard deviation of three experimental determinations. NS $(P>0.05$; Kruskal-Wallis rank-sum test). Abbreviation: NS, not significant. 
ready for freeze-drying. The advantage of freeze-drying is to maintain stability, thus allowing longer lasting conservation of nanocapsules. ${ }^{33}$

The average size of CHX-NC suspensions was in accordance with other NC-preparation methods, ${ }^{21}$ and microscopic observation showed that the CHX-NC structure was defined by a clear wall formed by polymer, as observed previously. ${ }^{19} \mathrm{EE}$ was found to be in the same range as previously described in the literature (ie, $50 \%-70 \%,{ }^{21} 60 \%{ }^{19}$ ) but was decreased by the freeze-drying process. Flocculation was assumed, since a decrease of backscattering was reported after gentle agitation of the CHX-NC suspension (data not shown). Furthermore, the positive charge at the surface of $\mathrm{CHX}-\mathrm{NCs}$, evidenced by zetapotential measurements, contributed to suspension stability.

The bactericidal effect of $\mathrm{CHX}-\mathrm{NC}$ was proved to be equivalent to that of solubilized CHX toward Gram-negative (E. coli) and Gram-positive (S. aureus) bacteria and fungi (C. albicans). Recently, antimicrobial silver-based nanomaterials have been reported, including nanoparticles, ${ }^{34,35}$ and in wound dressing and surgical sutures. ${ }^{36,37}$ However, their safety is often controversial, considering silver cytotoxicity on keratinocytes and fibroblasts ${ }^{38}$ and side effects (eg, cost, definitive tegument coloration). In contrast, the encapsulation of CHX limits drug diffusion into tissular and cellular structures, potentially reducing recurrent side effects by appropriate targeting against microorganisms. Furthermore, in a previous study, we reported that encapsulation of $\mathrm{CHX}$ enabled immediate and sustained antimicrobial activity against resident and transient skin flora. ${ }^{18}$ These results were explained by both adhesion properties of nanoparticles based on their physicochemical properties (eg, size, surface charge $)^{39}$ and controlled release of CHX from nanocapsules deposited onto the skin surface and accumulated in cutaneous appendages. ${ }^{40}$

Moreover, biocompatible and biodegradable polymer enhances the tolerance and safety of the formulation, ${ }^{17}$ and thermosensitive active pharmaceutical ingredient encapsulation, including peptidic structures, is claimed by substituting crystalline polymer (ie, PCL melting point $\sim 60^{\circ} \mathrm{C}$ ) with an amorphous low glass-transition temperature polymer (eg, poly[lactide-co-glycolide acid] glass-transition temperature $\sim 40^{\circ} \mathrm{C}$ ).

\section{Conclusion}

In the present study, a stable formulation of antimicrobial NCs produced by a new solvent-free method was successfully tested against several strains of bacteria. The simplicity of the process enables the industrial scale-up of ready-to use or freeze-dried products for widespread use in daily care practices, eg, in hand-washing hospital procedures or in dentistry. Eventually, such versatile nanoprocesses might encapsulate various chemical compounds for further pharmaceutical or cosmetic applications.

\section{Acknowledgment}

We acknowledge Aurélia Vettese (Nosoco Tech, Lyon) for her help with bacteriologic experiments and for giving us access to the equipment.

\section{Disclosure}

The formulation process described in this work is protected by a patent that belongs to the authors. The authors declare no conflicts of interest in this work.

\section{References}

1. McDonnell G, Russell AD. Antiseptics and disinfectants: activity, action, and resistance. Clin Microbiol Rev. 1999;12(1):147-179.

2. Hearnden V, Sankar V, Hull K, et al. New developments and opportunities in oral mucosal drug delivery for local and systemic disease. $A d v$ Drug Deliv Rev. 2012;64(1):16-28.

3. Ankola AV, Hebbal M, Mocherla M. A review of efficacy of various modes of chlorhexidine delivery. J Oral Biosci. 2008;50(4):239-242.

4. Jones CG. Chlorhexidine: is it still the gold standard? Periodontol 2000. 1997; 15:55-62.

5. Flotra L. Different modes of chlorhexidine application and related local side effects. J Periodontal Res Suppl. 1973;12:41-44.

6. Doury J, Falson F, Pirot F, Huynh TT, inventors; Université Claude Bernard Lyon I, assignee. Elastic orthodontic elements that can release poorly saliva-soluble chlorhexidine. Patent WO2011121224 A3. 2011 Dec 29.

7. Autio-Gold J. The role of chlorhexidine in caries prevention. Oper Dent. 2008;33(6):710-716.

8. Harris BD, Hanson C, Christy C, et al. Strict hand hygiene and other practices shortened stays and cut costs and mortality in a pediatric intensive care unit. Health Aff (Millwood). 2011;30(9):1751-1761.

9. Hassan M, Tuckman HP, Patrick RH, Kountz DS, Kohn JL. Cost of hospital-acquired infection. Hosp Top. 2010;88(3):82-89.

10. Johnson PD, Martin R, Burrell LJ, etal. Efficacy of an alcohol/chlorhexidine hand hygiene program in a hospital with high rates of nosocomial methicillin-resistant Staphylococcus aureus (MRSA) infection. Med J Aust. 2005;183(10):509-514.

11. Beausoleil CM, Paulson DS, Bogert A, Lewis GS. In vivo evaluation of the persistant [sic] and residual antimicrobial properties of three hand-scrub and hand-rub regimes in a simulated surgical environment. J Hosp Infect. 2012;81(4):283-287.

12. Widmer AF. Replace hand washing with use of a waterless alcohol hand rub? Clin Infect Dis. 2000;31(1):136-143.

13. Tapia-Jurado J, Reyes-Arellano W, García-García JJ, Jiménez-Corona JL, Peña-Jiménez CM, León-Mancilla B. [Comparative study of the cost/ effectiveness of surgical wash with various antiseptics]. Cir Cir. 2011;79(5):447-452. English and Spanish.

14. Widmer AF. Surgical hand hygiene: scrub or rub? J Hosp Infect. 2013; 83 Suppl 1:S35-S39.

15. Parienti JJ, Thibon P, Heller R, et al. Hand-rubbing with an aqueous alcoholic solution vs traditional surgical hand-scrubbing and 30-day surgical site infection rates: a randomized equivalence study. JAMA. 2002;288(6):722-727.

16. Hughes GA. Nanostructure-mediated drug delivery. Nanomedicine. 2005;1(1):22-30. 
17. Dash TK, Konkimalla VB. Poly- $\varepsilon$-caprolactone based formulations for drug delivery and tissue engineering. $J$ Control Release. 2012;158(1):15-33.

18. Nhung DT, Freydiere AM, Constant H, Falson F, Pirot F. Sustained antibacterial effect of a hand rub gel incorporating chlorhexdine-loaded nanocapsules (Nanochlorex). Int J Pharm. 2007;334(1-2):166-172.

19. Lboutounne H, Chaulet JF, Ploton C, Falson F, Pirot F. Sustained ex vivo skin antiseptic activity of chlorhexidine in poly(epsilon-caprolactone) nanocapsule encapsulated form and as a digluconate. J Control Release. 2002;82(2-3):319-334.

20. Lboutounne H, Faivre V, Falson F, Pirot F. Characterization of transport of chlorhexidine-loaded nanocapsules through hairless and Wistar rat skin. Skin Pharmacol Physiol. 2004;17(4):176-182.

21. Mora-Huertas CE, Fessi H, Elaissari A. Polymer-based nanocapsules for drug delivery. Int J Pharm. 2010;385(1-2):113-142.

22. Kanmani P, Lim ST. Synthesis and structural characterization of silver nanoparticles using bacterial exopolysaccharide and its antimicrobial activity against food and multidrug resistant pathogens. Process Biochem. 2013;48(7):1099-1106.

23. Kumar S, Singh M, Halder D, Mitra A. Mechanistic study of antibacterial activity of biologically synthesized silver nanocolloids. Colloids Surf A Physicochem Eng Asp. 2014;449:82-86.

24. Pirot F, Falson F, inventors; Université Claude Bernard Lyon 1, assignee. Novel method for producing nanocapsules in the absence of an organic solvent, and nanocapsules produced thereby. United States patent US 20110111019 A1. May 12, 2011

25. Salmon D, Pont E, Chevallard H, et al. Pharmaceutical and safety considerations of tablet crushing in patients undergoing enteral intubation. Int J Pharm. 2013;443(1-2):146-153.

26. Mengual O, Meunier G, Cayré I, Puech K, Snabre P. Turbiscan MA 2000: multiple light scattering measurement for concentrated emulsion and suspension instability analysis. Talanta. 1999;50(2): 445-456.

27. Huynh TT, Padois K, Sonvico F, et al. Characterization of a polyurethanebased controlled release system for local delivery of chlorhexidine diacetate. Eur J Pharm Biopharm. 2010;74(2):255-264.
28. Wannachaiyasit S, Phaechamud T. Development of chlorhexidine thermosensitive gels as a mouth antiseptic. J Met Mater Miner. 2010;20(3):165-168

29. European Directorate for the Quality of Medicines. Efficacy of antimicrobial preservation. In: European Pharmacopoeia. 8th ed. Strasbourg: EDQM; 2013:557.

30. Fessi H, Puisieux F, Devissaguet JP, Ammoury N, Benita S. Nanocapsule formation by interfacial polymer deposition following solvent displacement. Int J Pharm. 1989;55(1):R1-R4.

31. Quintanar-Guerrero D, Allémann E, Doelker E, Fessi H. Preparation and characterization of nanocapsules from preformed polymers by a new process based on emulsification-diffusion technique. Pharm Res. 1998;15(7):1056-1062.

32. Mehnert W, Mader K. Solid lipid nanoparticles: production, characterization and applications. Adv Drug Deliv Rev. 2001;47(2-3):165-196.

33. Abdelwahed W, Degobert G, Stainmesse S, Fessi H. Freeze-drying of nanoparticles: formulation, process and storage considerations. $A d v$ Drug Deliv Rev. 2006;58(15):1688-1713.

34. Kim JS, Kuk E, Yu KN, et al. Antimicrobial effects of silver nanoparticles. Nanomedicine. 2007;3(1):95-101.

35. Rai M, Yadav A, Gade A. Silver nanoparticles as a new generation of antimicrobials. Biotechnol Adv. 2009;27(1):76-83.

36. Ho CH, Odermatt EK, Berndt I, Tiller JC. Long-term active antimicrobial coatings for surgical sutures based on silver nanoparticles and hyperbranched polylysine. J Biomater Sci Polym Ed. 2013;24(13): $1589-1600$.

37. Ip M, Lui SL, Poon VK, Lung I, Burd A. Antimicrobial activities of silver dressings: an in vitro comparison. J Med Microbiol. 2006;55(Pt 1): 59-63.

38. Poon VK, Burd A. In vitro cytotoxity [sic] of silver: implication for clinical wound care. Burns. 2004;30(2):140-147.

39. Alvarez-Román R, Naik A, Kalia YN, Guy RH, Fessi H. Skin penetration and distribution of polymeric nanoparticles. J Control Release. 2004;99(1):53-62.

40. Papakostas D, Rancan F, Sterry W, Blume-Peytavi U, Vogt A. Nanoparticles in dermatology. Arch Dermatol Res. 2011;303(8):533-550.
International Journal of Nanomedicine

\section{Publish your work in this journal}

The International Journal of Nanomedicine is an international, peerreviewed journal focusing on the application of nanotechnology in diagnostics, therapeutics, and drug delivery systems throughout the biomedical field. This journal is indexed on PubMed Central, MedLine, CAS, SciSearch ${ }^{\circledR}$, Current Contents ${ }^{\circledR} /$ Clinical Medicine,

\section{Dovepress}

Journal Citation Reports/Science Edition, EMBase, Scopus and the Elsevier Bibliographic databases. The manuscript management system is completely online and includes a very quick and fair peer-review system, which is all easy to use. Visit http://www.dovepress.com/ testimonials.php to read real quotes from published authors. 